\title{
Public Policy Qualities and Training of New Engineering Talents in China - Based on the Practice and Enlightenment of EPP Professional Talent Training at Carnegie Mellon University
}

\author{
Yang Du*, Qingqing Yang \\ Guizhou University, Guiyang 550025, Guizhou Province, China \\ *Corresponding author: Yang Du, zivstuart@ foxmail.com
}

\begin{abstract}
As a measure for higher engineering education in the new era to deal with a new round of scientific and technological revolution and industrial reform, China's new engineering construction is an important strategic deployment to cultivate diversified and innovative engineering talents. In order to promote the new engineering construction in an allrounded way, talent training is the key. Compared with traditional engineering talents, new engineering talents need to have richer values and normative knowledge, especially public policy qualities, which is the ability that new engineering talents should have in this complex and changeable environment. The EPP (Engineering and Public Policy) professional training model at Carnegie Mellon University provides useful practical experience for the cultivation of public policy qualities of new engineering talents.
\end{abstract}

Keywords: New engineering talents; Public policy quality; EPP major of Carnegie Mellon University

Publication date: August 2021; Online publication: August 30, 2021

\section{Introduction}

New engineering education is a major reform measure carried out by China's higher educational institutions in their educational philosophy and practice in order to welcome the new economy characterized by new technologies, industries, and modes ${ }^{[1]}$. Compared with the traditional engineering discipline, the new engineering discipline has formed an interdisciplinary system with the progress and integration of different knowledge and technologies. Under the new engineering education concept, talent training should be characterized and guided by strategy, innovation, system, openness, as well as the shaping of diversified and innovative engineering talents. This kind of talent training is more in line with the development trend of engineering education and meets the practical needs of the economic and social development in this new era ${ }^{[2]}$. At present, the mutual penetration among disciplines reflects the needs of diversified talent knowledge. The education mode that is limited to the cultivation of pure technical quality among engineering talents is obviously old-fashioned. New talents with compound knowledge are becoming more and more popular. Cultivating engineering talents with diversified vision and systematic thinking has become a new requirement and goal in the innovation and reform of the education mode for engineering majors in colleges and universities. The new engineering does not only include a new engineering major, but also new requirements in engineering, which need to be integrated into the content of humanities and social sciences ${ }^{[3]}$. 


\section{Connotation and public policy qualities among new engineering talents}

\subsection{Basic connotation of public policy qualities of new engineering talents}

The new engineering is new to the traditional engineering education in terms of engineering education concept, discipline and specialty structure, talent cultivation mode, education, and teaching quality ${ }^{[4]}$. Many scholars, scientists, and policy advisers with relevant academic accomplishments and practical experiences feel that policy science has obvious interdisciplinary characteristics ${ }^{[5]}$. The public policy subject has strong discipline permeability, and its tasks include the human society, natural environment, engineering implementation, and other public fields. Naturally, the cultivation of public policy qualities of new engineering talents is not only a practical need for new engineering talents to actively respond to the complex environment in the future ${ }^{[6]}$, but also the basic requirement of the new engineering construction and development strategy. Public policy qualities refer to special qualities with the concept and perspective of "publicity," "sociality," and "universality." They are the internal qualities of each conscious subject. The public policy qualities of new engineering talents are mainly reflected in non-highly professional engineering talents but with scientific public policy knowledge network, which is an important part of interdisciplinary learning in addition to the crystallization of cultivating humanistic feelings and social science literacy among engineering talents.

\subsection{Public policy qualities of new engineering talents}

In view of the requirements of the new engineering construction strategy for talent training, the public policy qualities of new engineering talents should include general knowledge of public policy, public problems identification sensitivity, public spirit and social responsibility consciousness, as well as policy practice and risk assessment ability so as to serve the national strategy as well as to adapt to industrial needs and future development trends.

\subsubsection{General knowledge of public policy}

A Japanese scholar, Eugene B. Skolnikoff, combined public policy with its development process and stated, "Public policy indeed has a nature of engineering; different from basic disciplines," and, "Policy making also needs a basic discipline pillar, which is public policy" [5]. The term "general knowledge" corresponds to the English word "general," which has the meaning of general and ordinary. Understanding the term "general knowledge" from this aspect provides an insight into the basic and extensive characteristics of its meaning. For new engineering talents, the general public policy knowledge should emphasize the basic and instrumental nature. At the basic level, engineering talents need to master the introductory discourse of the public policy discipline, have an exploratory understanding of the basic concepts of policy science and policy analysis, the value of policy science, policy cycle process, as well as other contents, and form a basic framework of public policy awareness. The tool requirement should be rooted in the foundation, the extension of the foundation, and at the same time has high learning and application value. Such knowledge integrates the methods and knowledge of social science, natural science, engineering science, and other disciplines, in addition to the integration of norms, skills, and methods (such as policy analysis methods), with the organic combination of planning analysis, scheme selection, and plan implementation. For new engineering talents, it has more practical significance and development value.

\subsubsection{Sensitivity to the identification of public (policy) problems}

The identification of public problems is the logical starting point of policy analysis. Policy problems are objective facts, which result from the imbalance of social interests as well as conflicts between values and norms of behavior. After the introduction of a policy plan related to social engineering construction, 
traditional engineers are often not sensitive to the problems and goal orientation in relevant plans. They are also unable to scientifically sort and solve complex problems in projects; they treat the main problems and secondary problems vaguely and blindly discriminate the main aspects and secondary aspects of the problems. In addition to that, they are not able to make good use of engineering resources. All these result in the embarrassing dilemma of "optimal engineering efficiency but low social benefit."

The sensitivity to the identification of public (policy) problems is mainly reflected in several aspects. The first is the knowledge sensitivity of identifying the nature of the problem. When exposed to a problem, it is necessary to quickly determine whether the nature of the problem is "private," "public," or "policy" and then determine the scope, degree, characteristics, and expected attention input of the problem. The second is the sensitivity of the identification methods. Facing "public" and "policy" problems, it is necessary to reflect on the problems from a dual perspective which includes public management and engineering technology in order to warrant a more scientific, reasonable, and goal-oriented engineering construction, reduce the cost of knowledge and unreasonable wastage in engineering construction, as well as improve the social benefits of the project. The third is to identify the sensitivity in the thought process of the problem. This sensitivity requires new engineering talents to have the urgency of perceiving problems and the logic in analyzing them. On the one hand, they should pay attention and provide feedback on complex and changeable problems, while on the other hand, they should develop the thinking habit of asking "what" first and then discussing on how to proceed.

\subsubsection{Engineering service policy spirit}

In contrast to general policy knowledge and the ability to identify policy issues, the spirit of engineering service policy emphasizes the development of the subconscious level of new engineering talents and reflects the normative orientation. It is an internal quality of "publicity" and altruism ${ }^{[7]}$, and an organic fusion of public service motivation, public ethical core, and service spirit. New engineering talents with public service motivation should adhere to the value orientation of public interests and reflect on problems from the perspectives of the citizens, collectives, and the society. The characteristics of "publicity," fairness, and impartiality embodied in public ethics would have a far-reaching and lasting impact on the growth of engineering talents, strengthen their ability to maintain harmonious relations and state in engineering activities, form professional relations and professional ethics with good moral connotations, and eventually form a synthesis of several values and virtues, which would be condensed into a unique public service spirit for new engineering talents through continuous learning and practice.

The social responsibility consciousness of new engineering talents is in line with the connotation of engineering service policy spirit. The two complements one another and the former emphasizes the importance of "public responsibility." Social responsibility consciousness allows the new engineering talents to make rational judgments and perceptual choices based on the connection between practical problems and processes while adding a touch of color and humanistic feelings to pure technical thinking.

\subsubsection{Policy practice and risk assessment ability}

Compared with the above three public policy qualities, policy practice and risk assessment ability are more specific, especially in line with the practicality of engineers ${ }^{[8]}$. For new engineering talents, although their policy practice ability is not as professional as the bureaucratic level, they also need to understand the basic policy implementation process. Policy implementation is a complex process, in which its essence is in the interaction of multiple parties, including policy implementation subjects and policy target groups, under the established policy resources and environment. New engineering talents need to value information sharing and have excellent communication skills in the complex policy implementation process and 
environment. They also need to coordinate and effectively allocate relevant resources among multiple policy stakeholders, publicize social engineering, and ensure that commercial engineering is more compatible. In contrast to the identification of public issues in advance, risk assessment ability requires new engineering talents to be able to apply policy environment during the implementation of projects, have reasonable cognition and prediction of the possible expected consequences in the promotion of projects, monitor the implementation of projects from a non-technical perspective, as well as reduce the comprehensive probability of risk at the policy level in order to maximize the benefits of these projects.

\section{Goal orientation of engineering and public policy talent training at Carnegie Mellon University}

Founded in 1900, Carnegie Mellon University (CMU) is one of America's most prestigious research universities in the world. CMU advocates interdisciplinary academic exchange and cooperation among different disciplines as well as emphasizes the integration concept of multi-disciplinary knowledge ${ }^{[9]}$. CMU has formed its own general education theory and curriculum system, in which the Engineering and Public Policy (hereinafter referred to as EPP) talent training is a model for the shaping of new engineering talents.

\subsection{Professional training goals for CMU engineering and public policy undergraduates}

CMU has a clear plan in terms of training objectives and future career for the EPP undergraduates. From the EPP training goal of optimizing the school's traditional curriculum system in terms of vision and skills as well as training students' understanding and practice in the overlapping dimension of technology and society, it can be appreciated that these undergraduate talents are interdisciplinary and diversified talents with more social compatibility. In the EPP training program, students do not only learn the professional courses of traditional engineering, but also the combination of these traditional courses with special supplementary courses. In the course of cultivating EPP undergraduates, in addition to broadening the traditional technical analysis method in projects, the combination with the characteristics of social potential influencing factors and other contents directly related to public management are also included. EPP aims to enrich the policy content of traditional engineering by creating courses which address socially or politically relevant technical issues. As a result, EPP graduates would have the same professional skills as their traditional counterparts, but with more comprehensive technical and social thinking perspective along with a richer analytical capacity. At the same time, they would have the ability to solve practical problems in complex and interdisciplinary systems ${ }^{[10]}$.

\subsection{Basic quality requirements for graduates with engineering and public policy major from CMU}

According to the EPP program, the undergraduates will develop four types of abilities and qualities: professional engineering ability and quality, multidisciplinary ability and quality, comprehensive basic ability and quality, as well as other abilities and qualities after professional courses and social practice. Among them, professional engineering ability and quality is the core professional quality of EPP professionals. This is the collection of the pure engineering knowledge system, which includes the required knowledge of engineering disciplines and other related disciplines, highlighting the professionalism and applicability of engineering talents. Multidisciplinary ability and quality include the ability of talents to function in complex environments, solve comprehensive problems from a multidisciplinary perspective, as well as have a connection perspective in different fields, levels, and scopes. This quality focuses on the cognition and comprehensive analysis ability of engineering talents, in which it is a collection of important expanded knowledge system based on professional engineering ability and accomplishment. The content of comprehensive basic ability and quality is not much; graduates are required to have general and flexible soft skills, which are a collection of non-professional skills but highly applicable and developmental. This 
ability plays an important role in the social practice of talents. Other abilities and qualities after professional courses and social practice reflect that talents are able to keep pace with the times, follow the trend of development, as well as understand and master the information knowledge of the current society and their own roles.

\subsection{Curriculum system of EPP at Carnegie Mellon University}

The EPP undergraduate program at Carnegie Mellon University has five major directions, including chemical engineering and civil engineering. Non-technical courses of EPP are added to different majors. The curriculum system of the five professional directions is comprised of engineering courses, mathematics and science, EPP non-technical courses, and free elective courses. In its curriculum system, the traditional elective course of basic engineering is replaced by engineering and public policy so that students can be orientated toward diversified professional consciousness from the junior grade itself. Engineering statistics and quality control courses are added to mathematics and science courses, which do not only emphasize on the application ability of engineering talents, but also encourage them to pay attention to the quality level of engineering activities along with stimulating their sense of social mission and responsibility. Among the general courses, EPP includes the more important economics and policy courses with some basic skills courses of high professional equivalent to realize the broad cultivation of engineering talents. Under the free elective courses, EPP emphasizes talent practice and specially organizes project courses, which require talents to accurately and effectively apply the knowledge they have learned to engineering construction while taking these as course evaluations.

The characteristic of its professional training curriculum system lies in the cultivation of non-technical courses. The specially added courses have many objectives with moderate diversity, and they are able to cultivate new engineering talents with multidimensional perspectives. STPP (Science, Technology, and Public Policy) and T\&P (Technology and Policy) minor are the two courses supplemented by CMU according to students' situations and based on the traditional training concept. However, the cultivation goals are the same ${ }^{[11]}$. STPP has a highly professional curriculum system, a more diversified course nature, a larger course content, and a preference for theoretical learning. The curriculum system of T\&P minor is aimed at students who have professional foundation and are interested in engineering technology as well as public policy. The content of the course is minimal, in addition, it has an auxiliary nature biased toward practical learning.

From the perspective of specific curriculum, STPP curriculum system consists of a basic introductory course, professional core courses, science and technology policy courses, and summit courses. Among them, the basic introductory course comprises of two modules: introduction to engineering and public policy, as well as EPP sophomore seminar. The core courses include the principles of microeconomics, statistics elective, decision-making theory elective, writing and communication elective, science and technology policy elective, etc. The practical project course is also included. T \& P minor curriculum system does not clearly divide the nature of its curriculum. It requires students to have a certain foundation of economics and statistics. The curriculum includes introduction to engineering and public policy, decision-making methods of engineers and scientists, application methods of science and technology policy, EPP project course, as well as two elective courses of science and technology policy. In short, both types of curriculum systems do emphasize the status of public policy and management. 


\section{Enlightenment of EPP professional talent training at CMU for the training of public policy qualities in new engineering talents}

\subsection{Further clarifying the training objectives and ideas}

A clear goal and concept of talent training is the prerequisite of higher education innovation. Only by clearly defining the training objectives, the educational practice can be guided pertinently. To strengthen the training of new engineering talents is to cultivate diversified, compound, innovative, and outstanding engineering talents by constructing new educational concepts, models, and systems which are oriented to complex technological environment based on the national education development vision and strategy, needs of social talent ability, subject education and teaching resources, as well as other realities. In view of the EPP training at Carnegie Mellon University, there should be a certain breadth and depth in the curriculum for the training of public policy qualities in new engineering talents. It is not only necessary to cultivate students' scientific decision-making ability and policy problem analysis ability in complex environments, but also train their independent thinking skills and richly shape the value orientation in social public consciousness.

\subsection{Comprehensively optimizing and adjusting the curriculum system}

The EPP program at Carnegie Mellon University highly embodies an interdisciplinary characteristic. The school provides supplementary courses based on its own specialties to highlight the characteristics of the disciplines and fully meet the diverse demands of different subjects for the courses. Through this beneficial practical experience, the curriculum system for the training of new engineering talents should offer relevant interdisciplinary courses as well as scientifically and reasonably form a public policy curriculum system to meet the needs of students' policy analysis ability and level. Traditional routine classroom teaching can integrate practical experimental activities, such as policy debate, policy practice research, policy scenario simulation, and so on. Interdisciplinary courses combine and link various subjects based on their connotation values and qualities, stimulate students to contemplate about the relevance and commonality of knowledge among different modules, and assist them to learn in the application of knowledge.

\subsection{Developing scientific and standardized course quality standards}

There is a need to institutionalize curriculum quality requirements and implement quality control under the guidance of a system for scientific and standardized curriculum quality standards. In the process of implementing the curriculum quality standards, it is also necessary to ensure the seriousness of the system. In the process of talent cultivation of engineering and public policy majors at Carnegie Mellon University, a special management organization has been set up along with a series of course management means to ensure the course development and quality tracking ${ }^{[12]}$. In the process of formulating curriculum quality standards for the training of new engineering talents, different types of curriculum quality standards should be scientifically formulate based on the principle of serving teachers and students, including teaching requirements, learning requirements, assessment requirements, etc. Other than that, the responsibility of the school, teachers, and students should be clearly divided when forming the curriculum system. As a key factor in teaching, teachers are the direct factor that affect the teaching quality. A variety of evaluation methods should be adopted for their teaching courses in addition to comprehensively evaluate the effect of their curriculum investment, link the evaluation results with their performance appraisal, and promote the continuous improvement of teaching quality. 


\subsection{Promoting the construction of information-based education and teaching platform}

With the development of the internet, big data, cloud computing, and other technologies, there has been an impact on the traditional education and teaching mode. There is an urgent need to constantly explore new engineering education and teaching systems along with informatization. In order to encourage innovative learning among undergraduates, Carnegie Mellon University has introduced studio-based learning in eight interdisciplinary minor programs and 30 new interdisciplinary education courses, which is encouraged across the university, including the EPP program. In the case of insufficient teachers for the public quality training of new engineering talents, "Internet +" classroom teaching can be adopted while making full use of high-quality online course resources, such as school online, MOOCs (massive open online courses), UOOC, etc., and allow students to freely choose courses on different network platforms. Qualified engineering education institutions can also be encouraged to cooperatively develop new engineering and public policy network teaching platforms, such as intelligent government decision-making simulation platform and public policy simulation platform, for the improvement of public policy qualities. Last but not least, it is imperative to strive to improve the public policy qualities of new engineering talents along with informatization.

\section{Disclosure statement}

The authors declare that there is no conflict of interest.

\section{References}

[1] Chen Y, 2017, Challenges and Responses: Reflections on Engineering Practice Education under the Background of New Engineering. Journal of Nanjing University of Aeronautics and Astronautics (Social Science Edition), (4): 89-91.

[2] Monteiro F, Leite C, Rocha C, 2019, Ethical Education as a Pillar of the Future Role of Higher Education: Analyzing Its Presence in the Curricula of Engineering Courses. Futures, 111(2): 168-80.

[3] Wu Y, 2018, New Engineering: The Future of Higher Engineering Education: Strategic Thinking on the Future of Higher Education. Higher Engineering Education Research, (6): 7-9.

[4] Zhong D, 2017, Connotation and Action of New Engineering Construction. Research on Higher Engineering Education, (3): 1-6.

[5] Yan Q, 2002, On the Field of Public Policy Knowledge. Seeker, (6): 64-6.

[6] Cameron I, Engell S, Georgakis C, et al., 2019, Education in Process Systems Engineering: Why It Matters More Than Ever and How It Can Be Structured. Computers \& Chemical Engineering, 126(3): 102-12.

[7] Zhang S, Kong F, 2016, Shaping the Public Service Spirit from the Perspective of Public Service Motivation. Nanjing Social Sciences, (11): 81-7.

[8] Rasmussen K, Callan D, 2016, Schools of Public Policy and Executive Education: An Opportunity Missed?. Policy and Society, 35(4): 397-411.

[9] Zhang X, Xu L, 2016, The Evolution of the Concept and Practice of General Education Curriculum in Carnegie Mellon University. China University Teaching, (3): 91-6.

[10] Amon CH, Finger S, Siewiorek DP, et al., 1996, Integrating Design Education, Research and Practice at Carnegie Mellon: A Multi-disciplinary Course in Wearable Computers. Journal of Engineering Education, 85(4): 279-85. 
[11] Eaton CD, Hennessey KA, Koester C, 2012, Collaborative Teaching Clusters at Carnegie Mellon University. Cases on Higher Education Spaces Innovation Collaboration \& Technology, : 141-64.

[12] Davidson CI, Hendrickson CT, Matthews HS, 2007, Sustainable Engineering: A Sequence of Courses at Carnegie Mellon. International Journal of Engineering Education, 23(2): 287-93. 